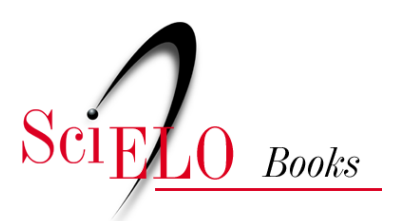

\title{
Cadastro único dos pobres por que e para quê?
}

\author{
José Carlos da Exaltação Torres
}

\section{SciELO Books / SciELO Livros / SciELO Libros}

TORRES, J.C.E. Cadastro único dos pobres: por que e para quê? In: Cadastro Único: tecnologia de reclassificação social [online]. Salvador: EDUFBA, 2016, pp. 227-235. ISBN: 978-65-5630-011-5. https://doi.org/10.7476/9786556300115.0012.

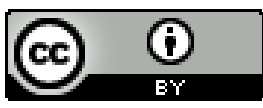

All the contents of this work, except where otherwise noted, is licensed under a Creative Commons Attribution 4.0 International license.

Todo o conteúdo deste trabalho, exceto quando houver ressalva, é publicado sob a licença Creative Commons Atribição 4.0. 


\section{CADASTRO ÚNICO DOS POBRES: POR QUE E PARA QUÊ?}

As alterações executadas sobre o Cadastro Único têm um caráter eminentemente técnico e demonstram a tentativa do governo de tornar mais racionais e eficientes as operações de identificação do público fundamental dos programas sociais focalizados. Trata-se de construir um instrumento público eficaz para auxiliar na gestão do problema da pobreza no Brasil. Isso fica demonstrado no depoimento de gestores e técnicos que participaram diretamente do processo de construção da base de dados do CadÚnico no âmbito nacional, e de outros que atuam nas atividades de manutenção desse cadastro e gestão dos benefícios do PBF. O presente capítulo privilegia esses depoimentos na construção de uma análise condensada do processo de construção e desenvolvimento do Cadastro Único, demonstrando a importância que esse cadastro assumiu sobre a ação pública no que tange ao tratamento dispensado à questão da pobreza no país, notadamente a sistematização de dados específicos e presumidamente censitários sobre o quantitativo e as condições de vida da população pobre do país, "foco" dos programas sociais de transferência de renda.

A análise sobre a evolução desses programas, desde o PETI, passando pelo Bolsa Escola, até o Bolsa Alimentação (implementados no Brasil entre 1996 e 2001), permite perceber que a "insuficiência de renda" não era o critério puro e simples para a concessão dos benefícios, uma vez que eram programas tematizados e se remetiam, em última instância, a situações de vulnerabilidade social condicionadoras, ou resultantes da condição de pobreza: ora ao trabalho infantil, ora à educação das crianças e adolescentes, ora à saúde nutricional. As suas características permitem interpretá-los 
como sendo programas complementares entre si, a exemplo do Bolsa Alimentação que se diferenciava do PETI e do Bolsa Escola, precisamente por sua vinculação à saúde e pelos critérios de elegibilidade das famílias a serem beneficiadas (com gestantes, nutrizes e crianças de seis meses a seis anos e onze meses de idade). Em todos os casos, os programas eram direcionados às famílias de "baixa renda", mas não todas elas, apenas aquelas em cuja composição havia crianças ou adolescentes.

Aí está a subjacente a noção de encaminhamento da saída da pobreza através de ações que promovam a interrupção do "ciclo intergeracional" de reprodução da pobreza, ou seja, que deem às crianças as condições de chegarem aonde seus pais não chegaram, de conseguirem ocupar uma posição social diferenciada da de seus antecessores, de oportunizar-lhes a condição de não pobres. Não obstante, esse corte etário na seleção de beneficiários constitui-se também num mecanismo adicional de "focalização", no desenho do público-alvo dos programas em questão. Por isso o cadastramento realizado para cada um desses programas se limitava a determinados membros de cada família, em geral a mãe (ou outro responsável) e até três filhos. Os dados coletados serviam essencialmente aos programas correspondentes, e assim, ainda que comportassem propriedades complementares entre si, cada programa cadastrava o seu próprio público e, dessa forma, as famílias consideradas pobres passavam por cadastramentos distintos que se superpunham no âmbito da administração pública. Esses cadastros se mostraram ferramentas frágeis para a avaliação dos resultados dos programas e mesmo para mensurar a sua cobertura.

Corrobora essa análise a descrição feita pela atual coordenadora de gestão de benefícios do PBF no MDS (janeiro 2010), em entrevista cedida para esta pesquisa (Ent. 3), sobre a estrutura fragmentada formada pelos programas "remanescentes" e os problemas que daí decorriam, tanto para a administração pública quanto para o público-alvo dos mesmos.

O que a gente tinha eram cadastros diferenciados, esforços diferenciados do governo federal, de manutenção daqueles dados tanto de cadastros quanto de beneficiários, a gente tinha estruturas administrativas diferentes, demandando esforços para administrar programas que se destinavam ao mesmo público. Por muitas vezes, várias famílias que recebiam todos os programas entre si, um monte de famílias que recebia um só. (Ent.3) 
O Cadastro Geral de Beneficiários do Bolsa Escola, base de dados do CadBES, pode ser considerado como a primeira tentativa de se construir um cadastro padronizado, referenciado num sistema de processamento informatizado, através do qual cada registro recebia um único código identificador, o NIS. Mas o CadBES, embora representasse um certo avanço enquanto ferramenta de "identificação" da população pobre, era também um cadastro específico e, portanto, limitado, registrando exclusivamente os beneficiários do Programa Bolsa Escola.

Você cadastrava nesse cadastro [CadBES] um responsável legal, uma pessoa da família, preferencialmente a mãe, e até três crianças. Quer dizer, independente da composição familiar você só podia cadastrar até três crianças [...]. Então a família tinha oito filhos, a mãe tinha que escolher quais eram os três filhos que ela cadastrava para receber o beneficio. (Ent. 3)

Em tese, os mecanismos de operação do CadBES servirão de modelo ao Cadastro Único, o que permitirá mais tarde a migração de seus dados para a base do CadÚnico, mas, em virtude da limitação do cadastro, essa operação estará obrigatoriamente condicionada à complementação dos dados, exigindo assim nova consulta às famílias beneficiárias daquele programa, ou a exclusão de seus registros.

É importante ressaltar que, além das características atribuídas ao público focalizado, os programas sociais em questão tinham também em comum a forma de sua execução, sempre delegada aos municípios, embora a gestão fosse centralizada em diferentes órgãos do governo federal. Dadas as peculiaridades regionais, as condições administrativas dos municípios e, sobretudo, a logística proporcionada pela União, os canais de comunicação estabelecidos entre os entes federativos para operacionalização desses programas eram deficientes, e as suas regras, pouco claras. Os municípios tinham, assim, uma larga autonomia sobre os mecanismos de seleção de beneficiários dos programas, com regras igualmente pouco claras entre os setores responsáveis por fazê-lo: Assistência Social, Educação e Saúde. Isso, aliado à persistência de relações políticas tradicionais - comuns aos municípios brasileiros -, fortemente pautadas no clientelismo, deu vagas não raramente ao uso político e eleitoreiro dos programas e à quase cristalização de uma disputa contínua por "listagens de pobres". Obviamente, isso não se deu dessa forma "nua e crua", como se diz popularmente, afi- 
nal os programas de transferência de renda incorporaram o mecanismo de criação de "instâncias de controle social", com o fito mesmo de fiscalizar e orientar esse processo. Contudo, embora as nuanças do controle social exercido nesse período extrapolem os limites do presente trabalho, importa observar, como bem analisou Edson Nunes (1997), que o clientelismo é um tipo de "gramática" política que se reinventa e se adapta às mais diferentes estruturas institucionais. Em suma, a operacionalização dos programas de transferência de renda tornava disperso o que se pretendia focalizado. Gerava deficiências no que se pretendia eficiente.

É desse cenário que emerge o Cadastro Único (BRASIL, 2001e); ele busca imprimir racionalidade à gestão dos programas sociais. Esses programas manterão as suas características, incluindo a gestão apartada em setores diferentes, mas a seleção de seus beneficiários deverá obedecer a um sistema comum de informações sociais, onde se atribuirá a cada indivíduo (como no CadBES) um código único de identificação, o NIS, a chave de unicidade do cadastro, sendo que a logística operacional deverá ser tratada por um colegiado dos órgãos gestores dos diferentes programas. (BRASIL, 2001a) Esse desenho parecia perfeito para corrigir os problemas identificados nos cadastros anteriores, principalmente no que diz respeito à sobreposição de benefícios. Mas não estavam aí discutidos os problemas existentes na execução do cadastro, no processo de cadastramento, na estrutura administrativa municipal. Da mesma forma, não se definiram, mais uma vez, mecanismos de comunicação eficientes entre a gestão e a operação do cadastro. O que seria a solução juntou-se, então, ao amontoado de problemas sentidos e vivenciados diretamente na esfera municipal.

Desde o final de 2001 e durante o ano 2002, o Cadastro Único passou por sua fase mais crítica, período este em que os municípios foram obrigados a se adaptar ao novo instrumental (formulários, softwares, equipamentos), imposto sem qualquer transição, sem qualquer teste sobre a realidade a ser aplicado, sem qualquer treinamento para a sua aplicação. Diante desse quadro, os resultados podiam ser antevistos, e se não foram enquanto se processavam, foram alvo de denúncias e discussões em diferentes instâncias, dentre as quais o TCU teve um papel de destaque. Antes do TCU, o CNAS, na voz de vários de seus conselheiros, já questionava o ônus do novo cadastramento sobre o município e as dificuldades para a sua realização (BRASIL, 2002h); o TCU, por sua vez, identificou inconsistências diversas, dados multiplicados, informações conflitantes e "obstáculos para a 
identificação de pessoas pobres". (BRASIL, 2003m, p. 19) Ainda em 2002, a equipe de transição de governo diagnosticaria o Cadastro Único como o "ponto de estrangulamento" na operacionalização dos programas sociais. Curiosamente, essa mesma equipe (ou parte dela), uma vez no Governo, voltará sua atenção aos programas e à estrutura institucional para a sua operação, mantendo intacto o Cadastro, como que um resquício das políticas sociais do governo anterior, crivado de erros e passível de ser descartado.

A criação do PBF, ao final de 2003, segue nesse sentido: é a busca da "efetividade" dos programas sociais, da eficácia na aplicação dos recursos públicos, da ruptura com a estrutura fragmentária mantida até então. Mas também significou, de acordo com a coordenadora de benefícios do MDS (Ent.3), um desafio para o Cadastro Único, porque a seleção de seus beneficiários dependia estritamente desse cadastro, e o Programa tinha metas a cumprir, assim, o Cadastro tinha que disponibilizar o quantitativo de famílias requerido pelo Programa; tarefa difícil, pelo fato de ele [o cadastro] ser pouco utilizado pelos municípios:

A família só podia entrar no Bolsa Família se tivesse seu cadastro pelo Cadastro Único, então, assim, o maior desafio do cadastro, que eu imagino, nessa época, foi subsidiar o Bolsa Família de famílias que pudessem ser beneficiárias. O Bolsa tinha uma demanda, 'olha, eu preciso atender tantas famílias esse ano', porque o crescimento foi gradual, e o cadastro tinha, para atender a essa demanda, que orientar os municípios no cadastramento de uma ferramenta que não era tão nova, mas não era utilizada, era uma ferramenta de 2001, mas era uma ferramenta muito pouco utilizada pelos municípios. (Ent. 3)

Esse depoimento expõe o que talvez seja uma das principais causas dos problemas gerados até aí: o Cadastro não era utilizado efetivamente e, assim, os seus dados não eram checados ou atualizados. Essa informação se reforça pelo depoimento de outra entrevistada, uma técnica de planejamento do IPEA, que já trabalhou na operação do Cadastro Único, no MDS (Ent.4). Segundo ela, até a criação do Bolsa Família, o CadÚnico "era meio uma coisa só no papel”, ele "não existia de fato". Mas, na sua interpretação, o desafio foi posto pelo Bolsa Família, que, para funcionar, precisaria "tornar o cadastro de melhor qualidade”. Essa associação entre CadÚnico e PBF parece ser uma visão relativamente consensual entre todas as entrevistadas, pois também a Assessora de Gabinete da SENARC, ex-coordenadora ge- 
ral do CadÚnico (Ent.5), ao ser inquirida sobre as dificuldades enfrentadas para implantação do Cadastro, remete-se diretamente ao período posterior à criação do Bolsa Família, às ações de qualificação dos dados do Cadastro Único. O que se extrai daí é que, ao se criar um novo programa dependente do CadÚnico, os problemas e dificuldades deste se tornaram comuns a ambos.

O Cadastro Único não é exclusivo do Bolsa Família, mas “o Bolsa” é considerado pelas entrevistadas como o seu programa estruturante. Segundo a interpretação da assessora da SENARC (Ent.5), foi essa associação que permitiu ao Cadastro alcançar o seu estágio atual, principalmente porque o Programa atende à maioria das famílias cadastradas, o que permite uma comunicação direta com as mesmas através de seus extratos bancários de pagamento de benefícios.

Se não fosse o Bolsa Família o cadastro não teria a qualidade que ele tem hoje, [...] a gente identificou os cadastros que estavam desatualizados há mais de dois anos e a gente identificou os beneficiários do Bolsa [Família], os beneficiários do Bolsa receberam mensagem no extrato, os beneficiários do Bolsa que não atualizaram até outubro tiveram o beneficio bloqueado. Então isso mobiliza que as pessoas vão lá [...] e atualizem. (Ent. 5)

Considerando o exposto, é possível dizer que o Bolsa Família deu utilidade ao Cadastro Único e simultaneamente revelou a sua importância. Até a criação do Programa, o Cadastro era desconhecido, inclusive para o próprio governo federal, que era formalmente o seu gestor, porque a base de dados ficava exclusivamente sob o controle da Caixa Econômica, o MDS não dispunha sequer de tecnologia para utilizá-la, sendo essa uma das principais dificuldades a se superar para fazer funcionar o processo de qualificação.

A gente teve dificuldades na própria secretaria, [...] a base [do cadastro] não ficava aqui, a base ficava só na Caixa, teve o esforço de internalização, teve o esforço de contratação de equipes de TI, teve o esforço de adquirir equipamento, não tinha, então foram grandes dificuldades. (Ent. 5)

Assim, a intenção do governo de instituir, a partir do Bolsa Família, uma "política nacional de transferência de renda" (de caráter equivalente a 
outras modalidades de políticas públicas vigentes) passava necessariamente pela "identificação" do público para o qual essa política se destinaria, e o Cadastro Único era a ferramenta pela qual isso se daria.

No fundo, o Cadastro Único, ele vem suprir uma lacuna que é dados para pobres, portanto, dados assistenciais, dados para políticas assistenciais. Os dados para as políticas de previdência já existem, estão lá na Dataprev, tem todo o cadastro, CNIS; [...] Aí tem as coisas da saúde toda, que são maravilhosas, em termos de os cadastros da saúde são espetaculares, eles têm toda uma base de dados que serve aos propósitos deles; A educação cada vez mais, está melhorando cada vez mais, [...] tem dado de tudo, cada vez mais, censo escolar... Cada área, as grandes áreas importantes têm os seus dados, os dados para fazer um programa de transferência dessa monta foi necessário usar um cadastro específico [...] Então, ele chama Cadastro Único, mas ele não é único, ele serve aos programas de transferência da assistência. (Ent. 4)

O entendimento é que, por meio desse Cadastro, os pobres "se tornam visíveis para a sociedade", uma vez que ele permite a "caracterização" de suas condições de vida (Entevistado 5).

[...] saber onde eles moram, saber em que condições eles vivem, saber o grau de escolaridade, saber mais informações. [...] dá mais racionalidade, eu acho, não é aquela coisa, você tira esse protecionismo... dá mais efetividade para o gasto público. (Ent.5)

De forma semelhante, o Cadastro é tido também como uma ferramenta que busca dar "homogeneidade no tratamento", superando a sobreposição de benefícios para algumas famílias em detrimento de outras, como ocorria anteriormente; ele dá "impessoalidade" na seleção de beneficiários, com critérios objetivos e transparentes, fora da esfera municipal.

A seleção é feita a nível nacional, então você acaba com a questão da pessoalidade e isso vai ao encontro [...] da política social não como um favor, como protecionismo ou clientelismo ou paternalismo, mas uma busca de acesso aos direitos, é direito de todo mundo ter acesso a renda, direito do acesso à saúde, educação, enfim. (Ent. 5) 
Todavia, essa impessoalidade no tratamento tem o seu reverso, porque o CadÚnico "identifica" cada membro da família com um NIS, e nesse código concentram-se as suas informações sociais fundamentais, permitindo que, por meio dele (contando que os dados sejam regularmente atualizados), o Estado lhe preste a assistência que julgue necessária, mas também que monitore a sua trajetória de vida sob a justificativa de acompanhar os estágios de desenvolvimento social das famílias pobres.

Então é assim, o atendimento da família completo, desde quando nasce, na verdade desde a gestante, até quando o menino completa dezoito anos ele ainda pode receber um beneficio ali, o atendimento é completo para a família inteira, você cadastra no Cadastro Único do Governo Federal, que é a base que a gente utiliza 'para escolher de lá os nossos beneficiários', toda a composição familiar, então é mãe, é pai, évó, é tio, todo mundo que mora naquela residência. (Ent. 3)

O “escolher” dos beneficiários a partir do Cadastro Único, como citado nesse depoimento, questiona esse cadastro enquanto ferramenta de seleção, porque ele mais ordena que separa. É dessa perspectiva que a técnica do IPEA (Ent.4) considera que a seleção se dá anteriormente, na definição do público-alvo dos programas que utilizarão o cadastro. "Ele é só o cadastro de um ordenamento das pessoas para um certo fim”.

O Cadastro, [...] ele não é propriamente, na minha visão, um instrumento de seleção de beneficiários. Ele é mais instrumento de cadastramento mesmo, 'de controle administrativo dos beneficiários'. [...] a seleção ela é auto-seleção, as pessoas que vão nas secretarias municipais de assistência, que vão nos postos do PBF; [...] tem um pouco de seleção que a prefeitura fez, porque ao escolher aquela escola ela escolheu algum tipo de gente; [...] é o papel das pessoas nesse processo, o papel das assistentes sociais, [...] o papel da propaganda em relação ao Bolsa [Família]. (Ent. 4)

Essa é uma observação importante e pode ser reforçada em comparação à orientação dada pelo MDS no manual para o SUAS (2006), destacando a fase de localização das famílias como uma seleção prévia das mesmas. Não se pode desconsiderar, porém, que também a formulação do Cadastro Único não é neutra, ela própria se sustenta numa concepção de mundo, numa forma de olhar uma determinada população, de localizá-la socialmente. 
A própria interpretação de que ele é um "instrumento de controle administrativo dos beneficiários" já sugere isso e o põe em equivalência a outras formas desenvolvidas historicamente para conhecimento de uma população, e mais precisamente para "gestão da pobreza", como analisou Valladares (2000) a respeito do conhecimento construído sobre as favelas cariocas em meados do século XIX. E o Cadastro é mesmo "uma ferramenta de gestão" que se pretende capaz de "mapear, dentro de cada município [...] onde estão, quem são, quais são e quantas são as famílias pobres”. (Ent. 3) 